(C)2003 Marcel Dekker, Inc. All rights reserved. This material may not be used or reproduced in any form without the express written permission of Marcel Dekker, Inc.

SYNTHETIC COMMUNICATIONS ${ }^{\circledR}$

Vol. 33, No. 10, pp. 1683-1693, 2003

\title{
Improved Synthesis of Amino Acid and Dipeptide Chloromethyl Esters Using Bromochloromethane
}

\author{
Paula Gomes, ${ }^{1, *}$ Maria Isabel Santos, ${ }^{2}$ Maria Joaquina Trigo, ${ }^{2}$ \\ Raquel Castanheiro, ${ }^{2}$ and Rui Moreira ${ }^{3}$ \\ ${ }^{1}$ Centro de Investigação em Química da Universidade \\ do Porto, and ${ }^{2}$ Departamento de Química da Faculdade \\ de Ciências do Porto, R. Campo Alegre, Porto, Portugal \\ ${ }^{3}$ Centro de Estudos de Ciências Farmacêuticas, \\ Faculdade de Farmácia, Universidade de Lisboa, \\ Lisboa, Portugal
}

\begin{abstract}
Peptide chloromethyl esters are important compounds in prodrug synthesis. A simple, mild and efficient method for the synthesis of chloromethyl esters of $N$-blocked amino acids and dipeptides using exclusively bromochloromethane is reported. These $N$-blocked amino acid and dipeptide chloromethyl esters react readily with the carboxylic acid group of aspirin and with the sulfonamido group of the antimalarial sulfamethazine, to give the corresponding prodrugs.
\end{abstract}

*Correspondence: Paula Gomes, Centro de Investigação em Química da Universidade do Porto, R. Campo Alegre, 687P-4169-007 Porto, Portugal; Fax: +351-226082959; E-mail: pgomes@fc.up.pt.

1683

DOI: $10.1081 /$ SCC-120018930

Copyright (c) 2003 by Marcel Dekker, Inc.
0039-7911 (Print); 1532-2432 (Online) www.dekker.com 
Key Words: Antimalarial; Aspirin; Bromochloromethane; Chloromethyl esters; Peptides; Prodrugs.

\section{RESEARCH REPORT}

The search for suitable prodrugs as chemical drug delivery systems is a high-priority task to overcome serious problems related to drug solubility, oral absorption, toxicity and metabolic inactivation. ${ }^{[1,2]}$ Amino acids are promising carriers in prodrug design, as they can improve water solubility and, thus, oral absorption of the drug. ${ }^{[3]}$ Dipeptides have also received attention as potential drug carriers to improve oral absorption, targeted to the dipeptide transporters present in the gastrointestinal tract. In this context, peptide chloromethyl esters are suitable coupling agents, capable of reacting with several nucleophilic groups frequently found in drugs, ${ }^{[4-6]}$ such as the carboxylic acid functionality.

In 1979, Wheeler and co-workers described the synthesis of $\mathrm{N}$-blocked amino acid chloromethyl esters [1] using triethylamine and chloroiodomethane (Fig. 1). ${ }^{[7]}$ However, they obtained rather low global yields $(9-25 \%)$ of [1] , and had to face the difficulties of separating the desired ester from large amounts of the gem-diester [2], also formed as a by-product. ${ }^{[7]}$ Recent work from Tsujihara's group describes an alternative synthetic route to $N$-blocked amino acid chloromethyl esters [1] using the reagent chloromethyl chlorosulfate, with good to excellent yields $(79-100 \%) .{ }^{[8]}$ Even though chloromethyl chlorosulfate is an excellent reagent for this reaction step, its synthesis occurs in modest yields (ca. 30\%) and involves hazardous reagents (chlorosulfonic acid) and products. ${ }^{[9]}$

We now wish to report an alternative method for the synthesis of $\mathrm{N}$-blocked amino acid chloromethyl esters [4], based on the reaction between the corresponding $N$-blocked amino acid caesium salts [3] and bromochloromethane (Fig. 2 and Table 1). Moreover, we have successfully extended this method to the synthesis of $N$-blocked dipeptide

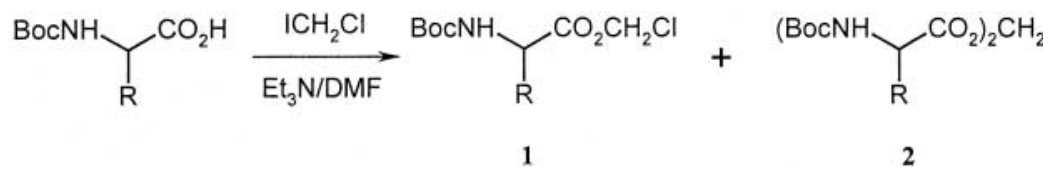

Figure 1. Synthetic route to chloromethyl esters by Wheeler and co-workers. ${ }^{[7]}$ 


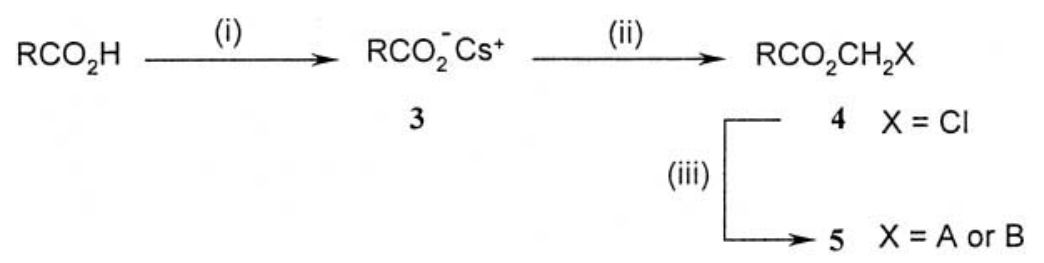

(i) $\mathrm{Cs}_{2} \mathrm{CO}_{3}$; (ii) $\mathrm{BrCH}_{2} \mathrm{Cl} / \mathrm{DMF}$; (iii) $\mathrm{ANa}^{+} / \mathrm{DMF}$ or $\mathrm{BH} / \mathrm{Et}_{3} \mathrm{~N} / \mathrm{DMF}$

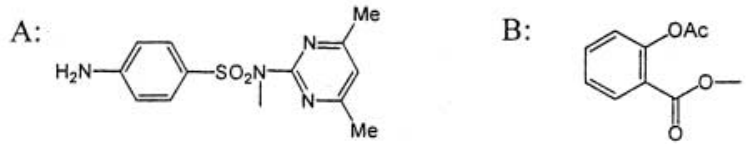

Figure 2. Synthetic route to potential sulfamethazine and aspirin prodrugs: (i) preparation of $N$-blocked amino acid and dipeptide caesium salts; (ii) synthesis of $\mathrm{N}$-blocked amino acid and dipeptide chloromethyl esters; (iii) derivatization of sulfamethazine and aspirin by reaction with amino acid and dipeptide chloromethyl esters.

chloromethyl esters [5] (Table 1). To our best knowledge, this is the first report on the synthesis of $N$-blocked dipeptide chloromethyl esters.

The method now described involves the previous preparation of the caesium salts of the $N$-protected amino acids and dipeptides, which were formed quantitatively from the corresponding $N$-protected amino acids and peptides. The use of caesium salts is known to improve the esterification rates and yields of amino acid chloromethylation when compared with the corresponding potassium, sodium, calcium or quaternary ammonium salts. ${ }^{[10,11]}$ The overall yields of [4] and [5] herein described range from 50 to $74 \%$ (Table 1), representing a significant improvement over the previous method using chloroiodomethane as the chloromethylating agent. ${ }^{[7]}$ The formation of the gem-diester [2] was almost completely suppressed, and thus it was easily separated from [4] or [5] by column chromatography.

The applicability of chloromethyl esters [4] and [5] in prodrug synthesis was assessed by preparing sulfamethazine and aspirin derivatives (Fig. 2). Chloromethyl esters [4] and [5] react readily both with the carboxylic acid group of aspirin and the sulfonamido group of the antimalarial sulfamethazine, to give the corresponding prodrugs with quite reasonable yields (ca. 40\%, Table 2). Interestingly, no cyclization of the $\mathrm{N}$-blocked dipeptide chloromethyl esters [5] was observed in the presence of the weak base sulfamethazine. 


\section{Gomes et al.}

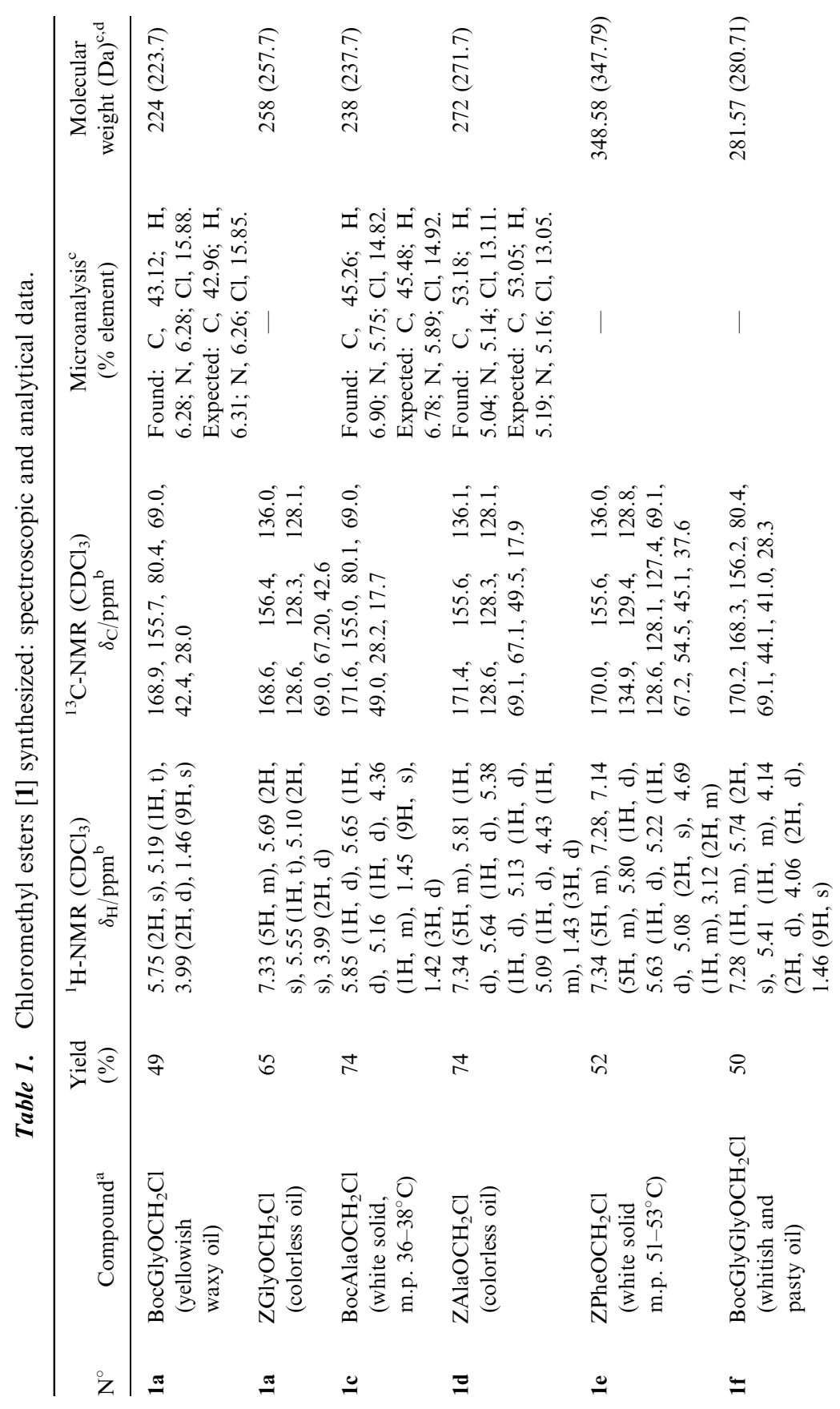


Peptide Chloromethyl Esters

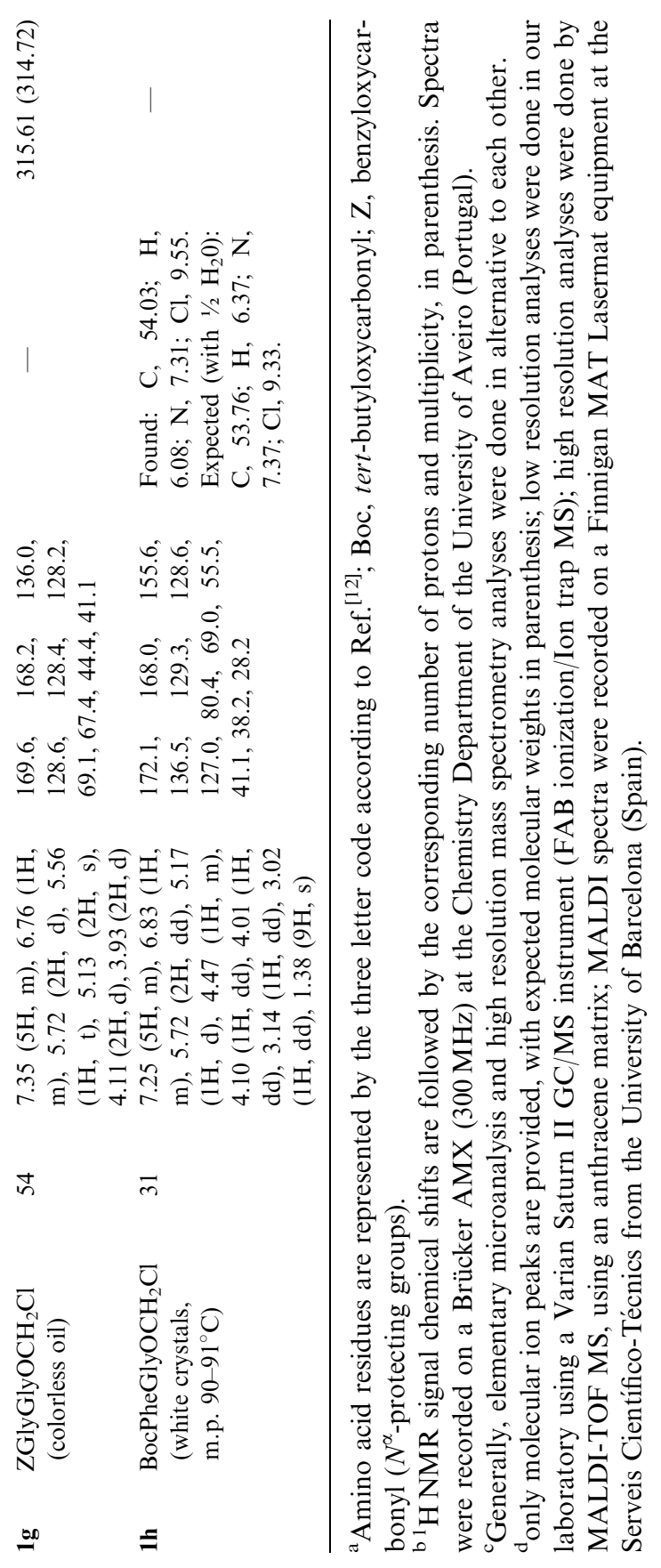


(C)2003 Marcel Dekker, Inc. All rights reserved. This material may not be used or reproduced in any form without the express written permission of Marcel Dekker, Inc.

1688

Gomes et al.

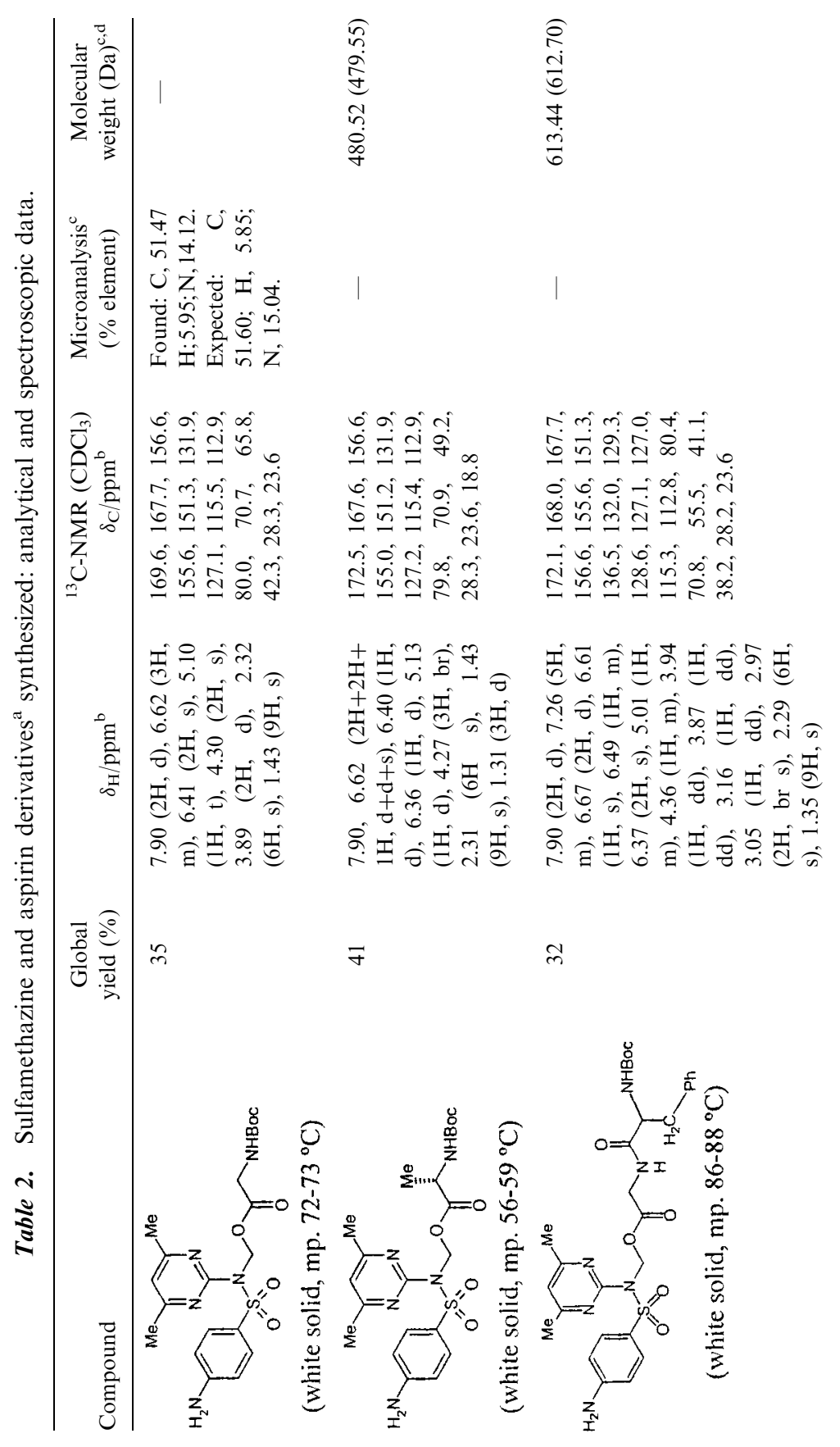


C일 2003 Marcel Dekker, Inc. All rights reserved. This material may not be used or reproduced in any form without the express written permission of Marcel Dekker, Inc.

Peptide Chloromethyl Esters

1689

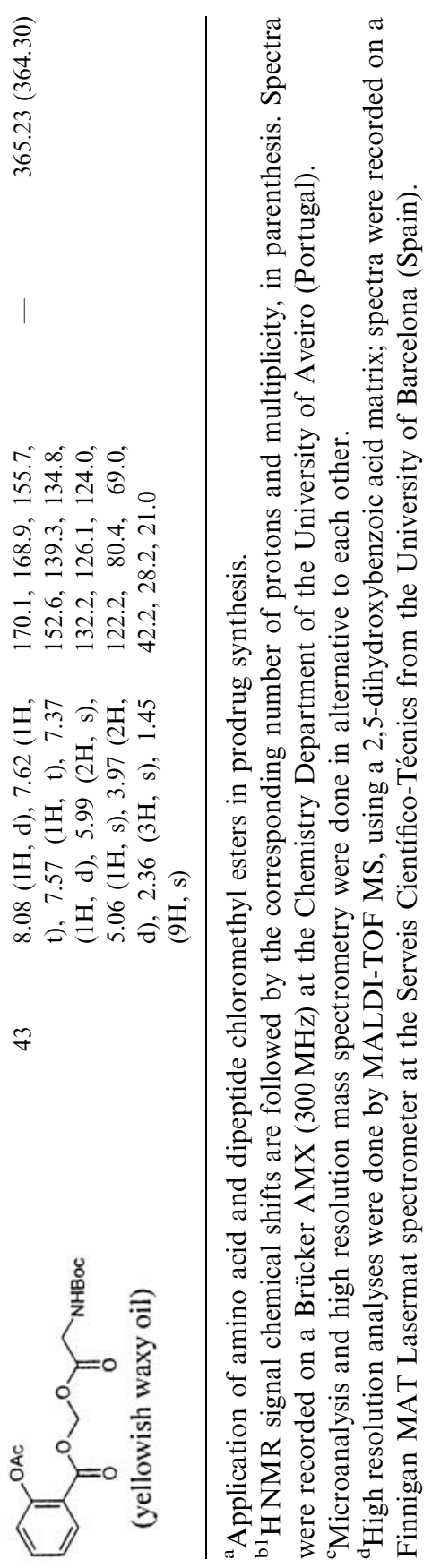




\section{EXPERIMENTAL SECTION}

\section{Synthesis of the $N$-Blocked Amino Acid/Dipeptide Caesium Salts}

The appropriate $N$-blocked amino acid or dipeptide $(5 \mathrm{mmol})$ was suspended in ethanol/water $7: 3 \mathrm{v} / \mathrm{v}(25 \mathrm{~mL})$ with magnetic stirring. The electrode of a $\mathrm{pH}$-meter was dipped into the solution and aqueous caesium carbonate $(1 \mathrm{M})$ was added dropwise until $\mathrm{pH} 6.5$ was reached. The solvents were then evaporated under low pressure and the resulting white caesium salt was allowed to dry in vacuum.

\section{Synthesis of the $N$-Blocked Amino Acid/Dipeptide Chloromethyl Esters}

Bromochloromethane $(35 \mathrm{~mL})$ was slowly added to a solution of the appropriate $N$-blocked amino acid/dipeptide caesium salt $(5 \mathrm{mmol})$ in dry $N, N^{\prime}$-dimethylformamide (DMF, $15 \mathrm{~mL}$ ), and the reaction was allowed to proceed in the dark at room temperature. After $20 \mathrm{~h}$, the caesium bromide formed was removed by suction filtration and filtrate was evaporated to dryness. The resulting mixture presented three components (thin layer chromatography, TLC), by increasing order of $R_{f}$, ceasium bromide, the gem-diester by-product and the main product. This main product was isolated by low pressure liquid chromatography (LPLC) on silica, using dichloromethane (DCM)/ethyl ether or DCM/acetone (in varying proportions) as eluents. Solid compounds were recrystallized from 1:1 ethyl ether/petroleum ether $\left(40-60^{\circ}\right)$ prior to analysis.

The identity and purity of the isolated chloromethyl esters were checked by ${ }^{1} \mathrm{H}$ and ${ }^{13} \mathrm{CNMR}, \mathrm{FAB} / \mathrm{Ion}$ Trap or MALDI-TOF MS and/or elemental analysis.

\section{Synthesis of the $N$-Blocked Amino Acid/Dipeptide Sulfamethazine Derivatives}

The sodium salt of sulfamethazine $(1 \mathrm{mmol})$ was slowly added to a solution of the appropriate $N$-blocked amino acid/dipeptide chloromethyl ester $(1 \mathrm{mmol})$ in dry DMF $(4 \mathrm{~mL})$. The reaction was allowed to proceed under constant stirring at room temperature, in the dark. After two days, the mixture was evaporated to dryness and the residue was redissolved in acetone $(2 \mathrm{~mL})$ upon heating. The solution was stored at $4^{\circ} \mathrm{C}$ overnight 
to promote the precipitation of sodium chloride, which was then removed by filtration under reduced pressure. The filtrate was evaporated to dryness and the resulting mixture revealed the presence of five to seven components (TLC), the main of which was isolated by LPLC on silica, using $\mathrm{DCM} /$ ethyl ether 1:1 as eluent. Isolated compounds were recrystallized from 1:1 ethyl ether/petroleum ether $\left(40-60^{\circ}\right)$ prior to analysis.

The structure and purity of the isolated compounds were confirmed by ${ }^{1} \mathrm{H}$ and ${ }^{13} \mathrm{CNMR}$, MALDI-TOF MS and/or elemental analysis.

\title{
Synthesis of the $N$-Blocked Amino Acid Acetylsalicilic Acid (“Aspirin") Derivatives
}

The $N$-blocked amino acid chloromethyl ester $(1 \mathrm{mmol})$ was dissolved in dry DMF $(2 \mathrm{~mL})$ and acetylsalicilic acid $(1 \mathrm{mmol})$ was added. Triethylamine $(1 \mathrm{mmol})$ was then added dropwise. The reaction was allowed to proceed under constant stirring at room temperature, in the dark. After three days, the triethylammonium chloride formed was removed by vacuum filtration and the filtrate was evaporated to dryness. The residue was redissolved in acetone $(2 \mathrm{~mL})$ upon heating and left to stand at $4^{\circ} \mathrm{C}$ overnight for additional precipitation of the triethylammonium salt. After a new cycle of salt filtration and filtrate evaporation to dryness, the mixture was submitted to LPLC on silica, with ethyl acetate as eluent. The target product was isolated and characterized by ${ }^{1} \mathrm{H}$ and ${ }^{13} \mathrm{C}$ NMR and by MALDI-TOF MS.

\begin{abstract}
ABBREVIATIONS
Boc, tert-butyloxycarbonyl; DCM, dichloromethane; DMF, $N, N^{\prime}$ dimethylformamide; FAB-MS, fast atom bombardment mass spectrometry; LPLC, low pressure liquid chromatography; MALDI-TOF MS, matrix-assisted laser desorption-time-of-flight mass spectrometry; NMR, nuclear magnetic resonance; PG, protecting group; TLC, thin layer chromatography; Z, benzyloxycarbonyl.
\end{abstract}

\section{ACKNOWLEDGMENTS}

The authors thank Fundação para a Ciência e Tecnologia for financial support (POCTI/FCB/39218/2001). PG thanks Dr. Adelina Macedo (Chemistry Department, Faculty of Sciences, University of Porto) for 
FAB/Ion Trap MS spectra. Special thanks to Drs. Eliandre de Oliveira, Judit Villén and Miquel Vila (Peptide Research Laboratory, University of Barcelona) for MALDI-TOF MS analyses.

\section{REFERENCES}

1. Korolkovas, A. Essentials of Medicinal Chemistry, 2nd Ed.; John Wiley \& Sons: New York, 1988.

2. Julien, R.M. Drugs and the Body; Atkinson, R.C., Lindzey, G., Thompson, R.F., Eds.; W. H. Freeman \& Co.: New York, 1987.

3. Hughes, R.A.; Toth, I.; Ward, P.; McColm, A.M.; Cox, D.M.; Andersson, G.J.; Gibbons, W.A. Lipidic peptides. 5. Penicillin and cephalosporin acid conjugates with increased lipophilic character. J. Pharm. Sci. 1992, 81 (8), 845-848.

4. Lopes, F.; Moreira, R.; Iley, J. Acyloxymethyl as a drug protecting group. Part 5: kinetics and mechanism of the hydroslysis of tertiary $N$-acyloxmethylsulfonamides. J. Chem. Soc., Perkin Trans. 2 1999, 431-439.

5. Lopes, F.; Moreira, R.; Iley, J. Acyloxymethyl as a drug protecting group. Part 6: $N$-acyloxymethyl- and $N$-[(aminocarbonyloxy)methyl]sulfonamides as prodrugs of agents containing a secondary sulfonamide group. Bioorg. Med. Chem. 2000, 8, 707-716.

6. Iley, J.; Barroso, H.; Moreira, R.; Lopes, F.; Calheiros, T. Acyloxymethyl as a drug protecting group. Part 7: tertiary sulfonamidomethyl ester prodrugs of benzylpenicillin: chemical hydrolysis and anti-bacterial activity. Bioorg. Med. Chem. 2000, 8, 1629-1636.

7. Wheeler, W.J.; Preston, D.A.; Wright, W.E.; Huffman, G.W.; Osborne, H.E.; Howard, D.P. Orally active esters of cephalosporin antibiotics. 3. Synthesis and biological properties of aminoacyloxymethyl esters of 7-[D-(-)-mandelamido]-3-[[(1-methyl-1H-tetrazol-5yl)thio]methyl]-3-cephem-4-carboxylic acid. J. Med. Chem. 1979, 22, 657-661.

8. Harada, N.; Hongu, M.; Tanaka, T.; Kawaguchi, T.; Hashiyama, T.; Tsujihara, K. A simple preparation of chloromethyl esters of the blocked amino acids. Synth. Comm. 1994, 24 (6), 767-778.

9. Binderup, E.; Hansen, E.T. Chlorosulfates as reagents in the synthesis of carboxylic acid esters under phase-transfer conditions. Synth. Comm. 1984, 14 (9), 857-864.

10. Gisin, B.F. The preparation of Merrifield-Resins through total esterification with cesium salts. Helv. Chim. Acta 1973, 56 (5), 1476-1482. 
○2003 Marcel Dekker, Inc. All rights reserved. This material may not be used or reproduced in any form without the express written permission of Marcel Dekker, Inc.

11. Martínez, J.; Laur, J.; Castro, B. Carboxamidomethyl esters (CAM esters) as carboxyl protecting groups. Tetrahedron Lett. 1983, 24 (47), 5219-5222.

12. Biochemistry Nomenclature Committee of the IUPAC-IUB (specified in Eur. J. Biochem. 1984, 138, 9 and in J. Biol. Chem. 1989, 264, 633).

Received in the UK May 14, 2002 


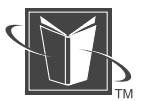

Marcel DekKer, Inc. • 270 Madison AVEnUe • NeW York, NY 10016

C일 2003 Marcel Dekker, Inc. All rights reserved. This material may not be used or reproduced in any form without the express written permission of Marcel Dekker, Inc. 